\title{
Histologic Analysis of Bone Development of the Florida manatee, Trichechus manatus latirostris
}

SC Connecticut

$\underline{\text { SU }}$ State University

Rachel Kelsall ${ }^{1}$, Jasper Han ${ }^{1}$, Stephanie Richard ${ }^{1}$, and Meghan Barboza ${ }^{1}$, PhD

\section{Introduction}

The amount of bone tissue present in an organism does not remain constant throughout a lifetime. Peak bone volume is understood to be achieved during biological development, with bone degradation to follow in adulthood ${ }^{1}$. Aquatic mammals generally have more dense bones than their terrestrial counterparts ${ }^{2}$ and there is little to no information on aquatic mammal bone development. The Florida manatee is a fully aquatic mammal which represents a good example of dense, amedullary bones ${ }^{3}$. The abundance of prominent bone tissue histological features such as osteocytes, mesenchyme, and trabeculae provide a mechanism to determine how bone tissue of the same species differs due to age. The ultimate goal of this study was to evaluate key histological differences between bone samples, from manatees of various ages, in order to approximate the age using characteristics of the bone tissue.

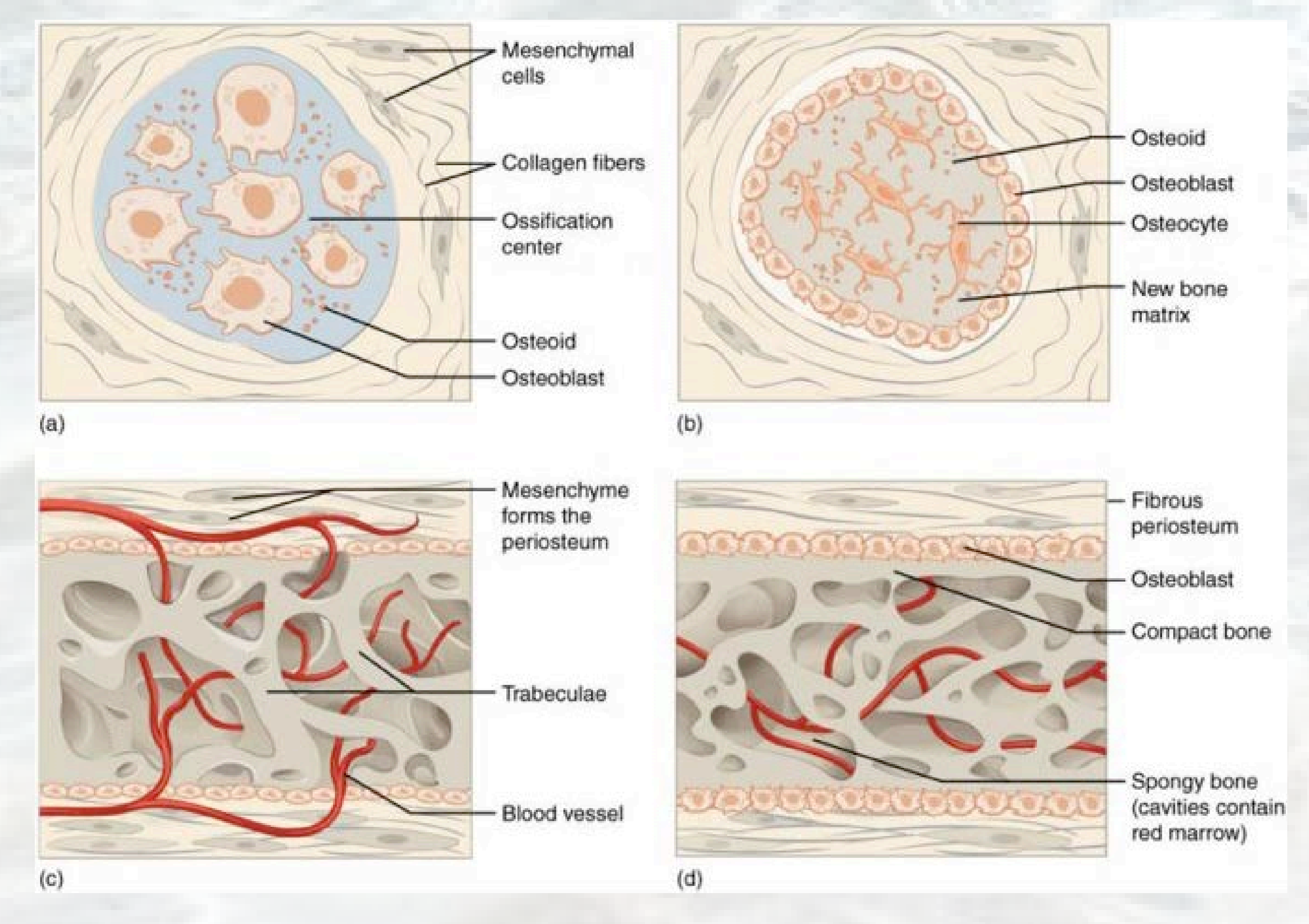

Figure 1. Intramembraneous ossification: (a) Ossification center is formed from grouping mesenchymal cells. (b) Osteoblasts become trapped within osteoid and turn into osteocytes. (c) Trabecular matrix and periosteum are formed. (d) Compact bone develops surroundnng trabeculae, blood vessels become red bone marrow. ${ }^{4}$ As published

\section{Materials and Methods}

-Samples: Nasal tissue including bone from manatees in the perinatal, calf, juvenile, and adult stages of development as determined by the animals length ${ }^{5}$. Collected under permit MA067116-2.

- Paraffin blocks sectioned at 5 micrometers using a microtome.

- Sections mounted, dried, and stained with trichrome stain.

- Slides observed with light microscopy and photographed at $40 \mathrm{X}$ and $100 \mathrm{X}$ magnification.

- Osteocyte lacunae were counted in the field of view of each photograph.

${ }^{1}$ Southern Connecticut State University

$\underline{\text { Results }}$

$100 X$

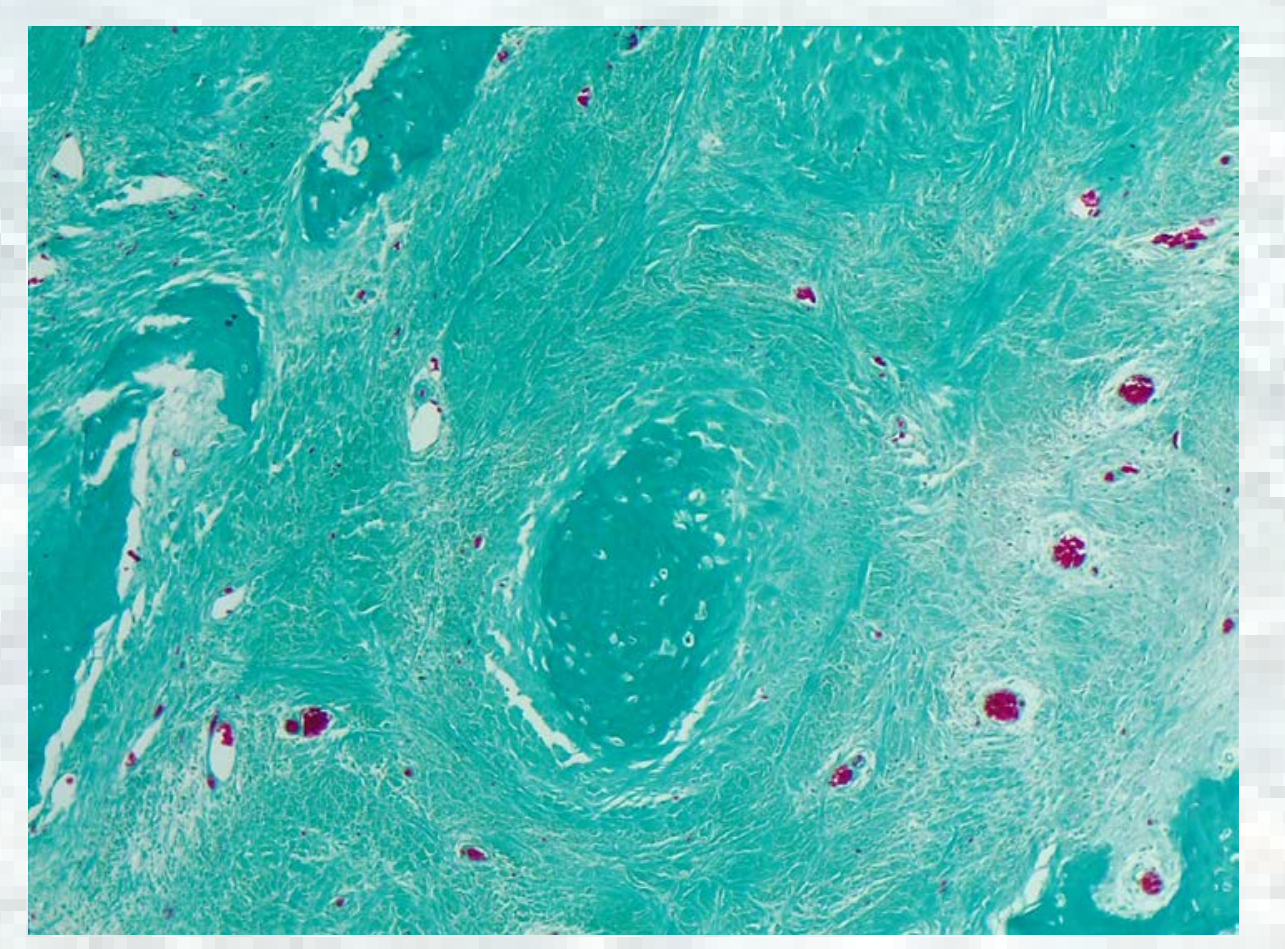

Calf

Juvenile
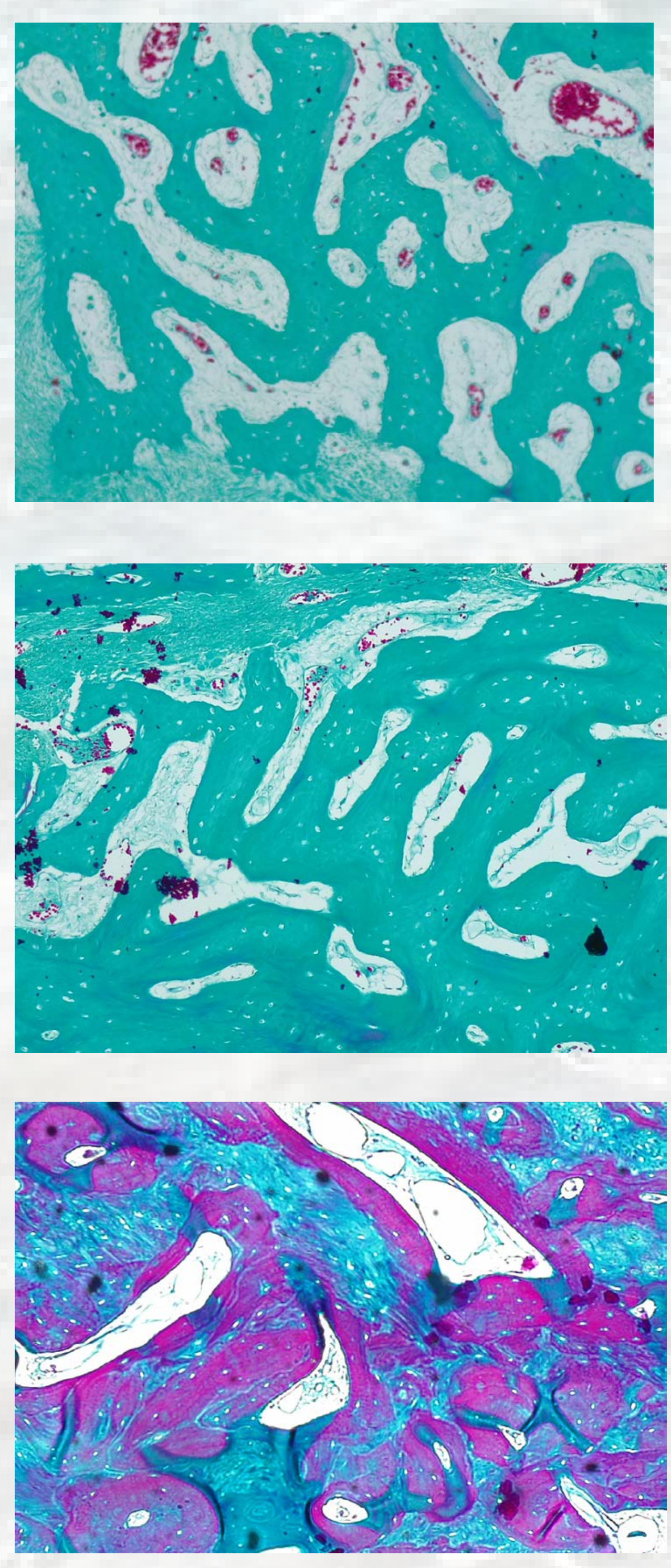

Figure 2. Trichrome stained nasal tissue and bo

Number of Osteocytes at 40x \& 100x Total Magnification
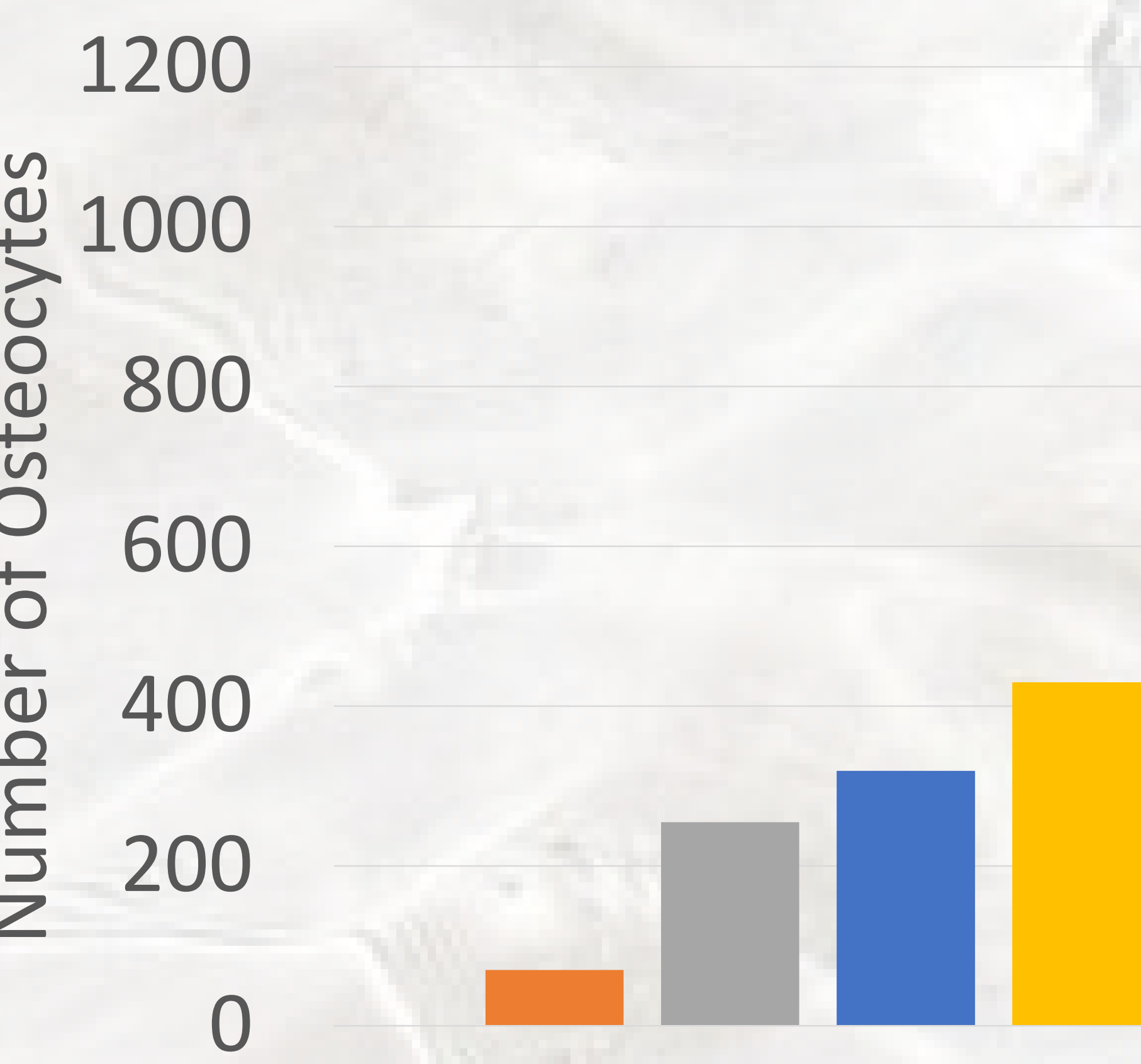

$100 x$

\section{Discussion}

Analysis of the osteocyte quantity using a chi square test for goodness of fit shows a significant trend $\left(p<2.2^{*} 10^{-16}\right)$ directly corresponding to the age of manatee. As the age of manatee increased, greater amounts of osteocytes were counted. Further observations indicate trabeculae are more abundant and prominent in early developmental stages (perinatal and calf) compared to the latter stages (juvenile and adult) in which mature or secondary bone is predominant. Using visual approximation, adult bone contained the largest bone volume, but showed minor signs of degradation and degeneration by osteoclast activity. These results are in greement with the available information regarding intramembranous bone development, and successfully show a proportional relationship between age and osteocyte number. More specific data, such as the exact age of manatee and computer calculated bone volume/osteocyte lacunae count, would allow us to further model this determined correlation between bone volume and age.

\section{Conclusions}

In this work, we investigated the relationship between the relative age of a manatee and bone volume. Our findings agree with prior research on osteocyte population as a determinant of bone volume ${ }^{6}$. We conclude that as age increases, osteocyte population (thus bone volume) increases. Future research will include an increased samples size to codify these trends and allow for detailed comparison between developmental ages.

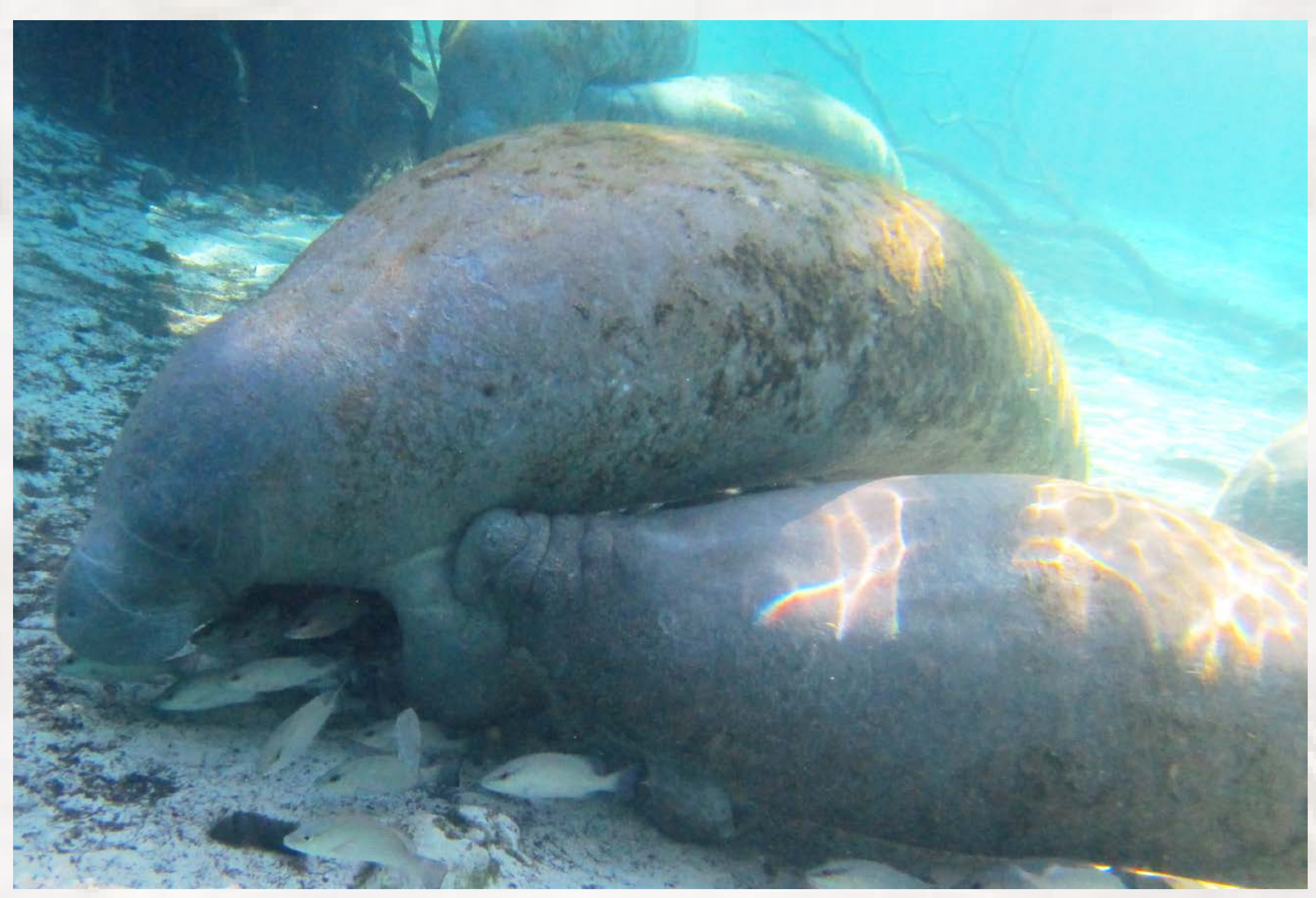

References

Perinatal 1.Boskey, A. L., \& R. Coleman. Aging and bone. J. of dental research 89.12 (2010): 1333-1348. 2.Wall, W. The correlation between high limb density and aquatic habitats in recent mammals. J. of Calf

- Juvenile

Adult

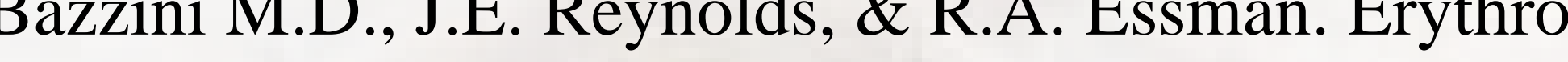

A Bone Formation and Development | Anatomy

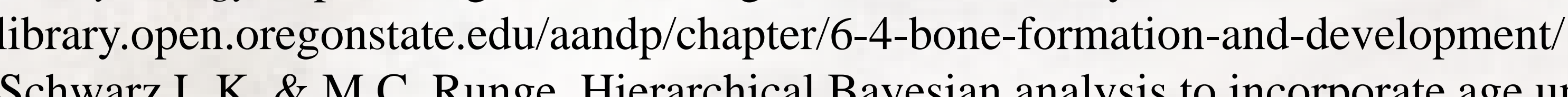
growth curve analysis and estimates of age from length: Florida manatee (Trichechus manatus) carcasses. Canadian J. of Fisheries and Aquatic Sciences. 66.10 (2009) 1775-1789. Vashishth, D., et al. "Determination of bone volume by osteocyte population." The Anatomical
Record: An Official Publication of the American Association of Anatomists 267.4 (2002): 292-295. 